\title{
Precursor-Like Anomalies prior to the 2008 Wenchuan Earthquake: A Critical-but-Constructive Review
}

\author{
Tengfei Ma and Zhongliang Wu \\ Institute of Geophysics, China Earthquake Administration, Beijing 100081, China \\ Correspondence should be addressed to Zhongliang Wu, wuzl@cea-igp.ac.cn
}

Received 7 August 2011; Accepted 31 October 2011

Academic Editor: Rodolfo Console

Copyright ( $) 2012$ T. Ma and Z. Wu. This is an open access article distributed under the Creative Commons Attribution License, which permits unrestricted use, distribution, and reproduction in any medium, provided the original work is properly cited.

Results published since the last three years on the observations of the precursor-like anomalies before the May 12, 2008, Wenchuan, $M_{s} 8.0$ earthquake are collected and analyzed. These retrospective case studies would have provided heuristic clues about the preparation process of this inland great earthquake and the predictability of this destructive event if the standards for the rigorous test of earthquake forecast schemes were strictly observed. At least in some of these studies, however, several issues still need to be further examined to confirm or falsify the connection of the reported observations with the Wenchuan earthquake. Some of the problems are due to the inevitable limitation of observational infrastructure at the recent time, but some of the problems are due to the lack of communication about the test of earthquake forecast schemes. For the interdisciplinary studies on earthquake forecast, reminding of the latter issue seems of special importance for promoting the works and cooperation in this field.

\section{Introduction}

At least partly due to the tremendous loss of life and property and the intense social impact [1], the Wenchuan earthquake that occurred on May 12, 2008, in Sichuan Province of southwest China, has attracted widespread attention not only in seismological communities but also in other scientific communities. Since the occurrence of the Wenchuan earthquake, there have been some 300 papers published related to the precursor-like anomaly observations prior to this great earthquake, making it necessary for a systematic collection and comprehensive analysis of these materials. The necessity of such collection and analysis is further highlighted by the fact that over 3/4 of these publications are in Chinese with/ without English abstract (with some of them being similar to, or just simply a repetition of the English publications) and quite a few of these publications are actually not known to international seismological communities. This is, similar to the situation of other developing countries [2], a characteristic of the scientific publications in China.

In the study of earthquake forecast/prediction, China seems of special features in that earthquake forecast/prediction has been kept for a long time as a nationwide scientific goal, even if there were intense debates on the predictability of earthquakes in the international seismological communities [3]. From merely the number of papers published, the Wenchuan earthquake might be one of the special, or even unique, events with so many studies on its forecast or preshock anomalies. If these anomalies could be confirmed, it would be an important event in the study on earthquake predictability; otherwise if these anomalies could not be confirmed, then it would be a useful sample for reminding of how the studies on earthquake forecast/prediction should be conducted in an efficient way. After the Wenchuan earthquake, there have been several studies trying to collect, compare, and analyze the (published and/or internal) data, including the data from the authors themselves (e.g., [4-11]). There are also some papers on the reflection of the earthquake forecast/prediction approaches based on the lessons of this earthquake $[3,12-15]$, with a diversity of ideas and data. The present paper is, to much extent, a continuation and extension of such collection and analysis works, but with different emphases in the analysis, highlighting the test of earthquake forecast/prediction schemes, and with a wider range of collection stressing interdisciplinary studies. 


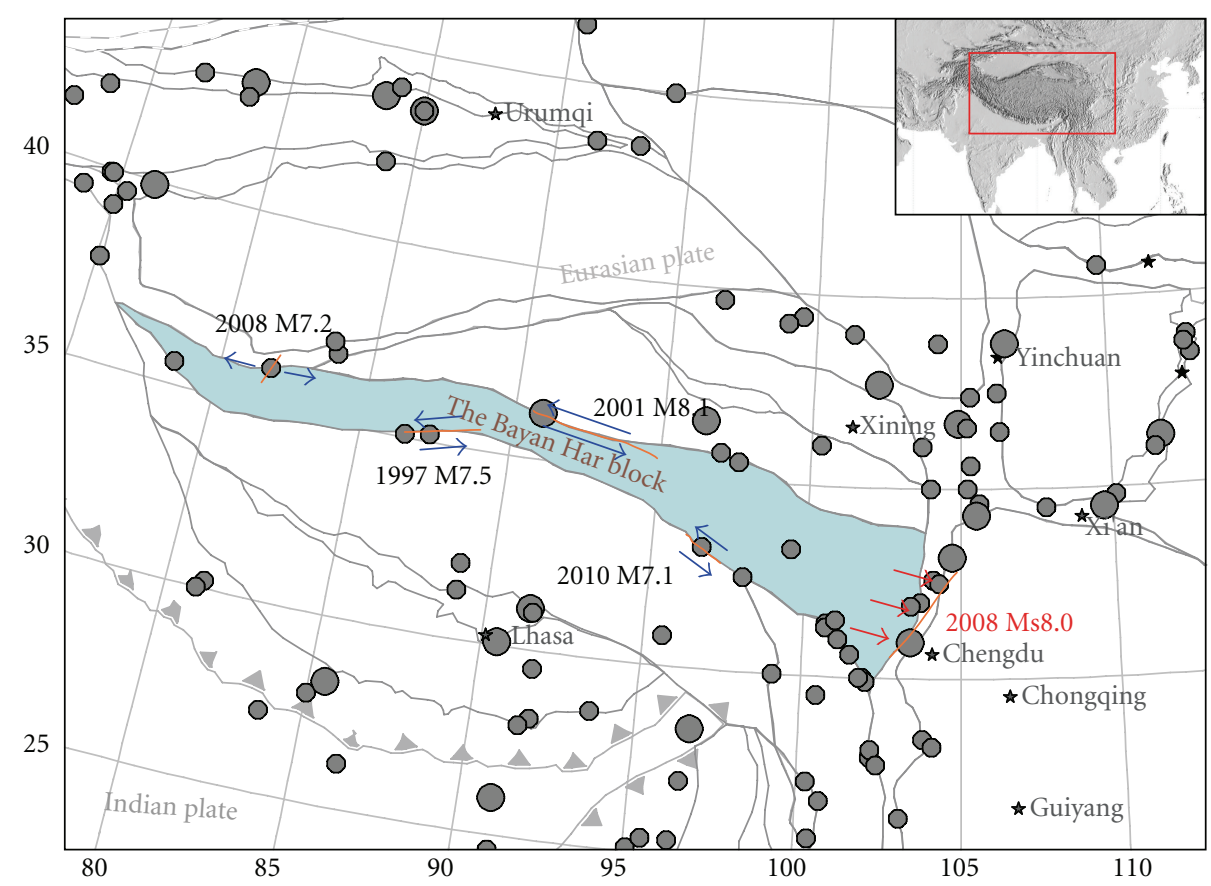

FIGURE 1: Distribution of major-to-great earthquakes around the Bayan Har block since 1997, with the 2008 Wenchuan earthquake located to the east, as shown by the text and arrows in red. To the top right is the indexing figure showing the position of the map. In the figure, orange lines show the earthquake ruptures, and blue arrows show the focal mechanism types of the earthquakes. Gray dots show the epicenters of historical major to great earthquakes. Gray solid lines indicate the boundaries of the tectonic blocks (according to [19]), with the Bayan Har block highlighted in the figure.

\section{Materials Collected and Used for the Analysis}

Although it has been only three years since the 2008 Wenchuan earthquake, because publications related to the precursor-like anomalies are within different research fields, the collection of such publications is still difficult to be completed. The collecting process was in two steps. For the materials published in English, searching terms " $(\mathrm{ti}=$ Wenchuan or $\mathrm{ts}=$ Wenchuan) and ( $\mathrm{ti}=$ precursor or $\mathrm{ts}=$ precursor or $\mathrm{ti}=$ before or $\mathrm{ts}=$ before or $\mathrm{ti}=$ prior or $\mathrm{ts}=$ prior)" were used to the SCI-E database via the Web of Science (http://www.isiknowledge.com/). From 2008 to mid2011, a total of 151 results hit the search. Removing the terms not directly related to the main topics, which are basically on the subjects of earthquake engineering and geological disasters, 61 articles were selected. For the materials published in Chinese, the China National Knowledge Infrastructure (CNKI) database (http://www.cnki.net/) was used with ("topic/title/keywords" = "(wenchuan) and (precursor or before or prior to)", in Chinese) as the search terms. Another two databases, the VIP database (http://www.cqvip.com/) and the Wanfang database (http://www.wanfangdata.com.cn/), were used as complementary sources. Using the screening criteria similar to that of the English publications, 261 articles in Chinese were collected. Abstracts of symposia [1618] are not included, since most of the results were published after these meetings. Due to the same reason, diplomatic theses are not included in the References. We eliminated the "repeated publications" as much as we could. If there are two papers with exactly the same contents in English and in Chinese, respectively, we just keep the English one in the reference list. If there were two papers, with extremely similar contents and similar author teams, but published in different journals, then we just leave one of them (in the journal with higher impact factors) in the reference list. To keep the paper as concise as it could be, we also screened out the publications which are concentrating on the mechanisms of the phenomenology based on other studies rather than providing the ("fresh") phenomenological report.

Ranking by the number of papers published, these papers appear mainly in Journal of Geodesy and Geophysics (Wuhan, with the English edition Geodesy and Geophysics), Earthquake (Beijing), Acta Seismologica Sinica (the Bulletin of the Seismological Society of China, Beijing, with the English edition Acta Seismologica Sinica, changing to Earthquake Science since 2009), and Chinese Journal of Geophysics (the Bulletin of the Chinese Geophysical Society, Beijing, with the English edition Acta Geophysica Sinica or Chinese Journal of Geophysics), publishing no less than 15 papers in each of them. Journals publishing the related papers numbers up to 53, reflecting the diversity of the related results.

\section{Characteristic Anomalies Reported and Characteristic Time Scales}

As a background of the geology and seismicity related to the Wenchuan earthquake, Figure 1 shows the distribution and 
size of the major-to-great earthquakes around the Bayan Har block since 1997 (using the earthquake catalogue from the China Earthquake Networks Center (CENC)). During this time period, the Bayan Har block is the unique contributor to the major-to-great earthquake activity in continental China. Before this period, for more than 2 decades, there was no major-to-great earthquake occurring around the Bayan Har block. This provides the concepts of the geodynamic origin of the Wenchuan earthquake, and its preparation process.

Precursor-like anomalies, observed at different time scales prior to the Wenchuan earthquake, are in a wide range. Following is a brief summary of the main observations.

3.1. Anomalous Seismicity. Decade-scale quiescence along the Longmenshan fault zone [20, 21]; variation of monthly number of earthquakes since 2000 along the Longmenshan fault zone [22]; six-and-half-year-scale gap of seismicity above $M_{L} 4.0$, disrupted 1 year before the Wenchuan earthquake [23]; five-year-scale PI "hotspots" along the Longmenshan fault zone, and five-year-scale "accelerating seismic release (ASR)" [21, 24, 25]; five-year-scale preshock increasing activity of intermediate-depth earthquakes [26]; threeyear scale quiescence of seismicity above $M_{L} 6.0[10,27]$; three-year-scale large-range seismicity pattern [28]; one-tothree-year-scale variation of "load-unload response ratio (LURR)" presented by seismicity [29, 30]; variation of "modulated earthquakes" 2 years before the Wenchuan earthquake [31]; two-year-scale variation of the homogeneity in seismicity [32]; variation of several statistical parameters of seismicity since the beginning of 2008 [33, 34]; half-year-scale seismic activation identified by PI method [35]. Besides, there are also studies on the potential tidal triggering effect which determines the origin time of the earthquake [36], and relation between Earth rotation and microseismicity [37].

3.2. Anomalies in Deformation Measurement. Decade-scale "locking" along the Longmenshan fault [38-40]; tilt variation from 2005 to 2006 [41]; accelerating fault activity since 2006 [42]; three-to-one-year-scale accelerating deformation [43]; “Oscillation anomalies" of GPS time series since 2007 [44]; one-year scale GPS baseline variation [45]; anomalous changes near the epicenter recorded by tiltmeter, since November 2007 [5]; anomalies of deformation (with resolution 3 months) before the Wenchuan earthquake identified retrospectively by wavelet analysis [46]; anomalies of tilt tidal factor in Shaanxi 3 months prior to the earthquake [47]; half-month-scale anomalous tilt [48]; and anomalies of deformation 3 days and 1 hour before the Wenchuan earthquake [40].

3.3. Anomalies in Strain/Stress Measurements. Five-year-scale perturbation of regional stress field before the Wenchuan earthquake by focal mechanism data [49]; increasing compressional strain since 2004 [50]; two-year-scale increase of regional stress [51]; two-year-scale micro-earthquake swarm, with focal mechanisms approaching to homogeneous [52]; months-to-year-scale disturbance in borehole strain measurement [53] and change of predominant focal-mechanisms of small earthquakes [54]; strain anomalies 3 months before the earthquake, with dominant frequencies depending on the epicentral distance [55]; changes of crustal stress since the end of April, 2008 [11]; week-scale variation of in-situ stress [56]; anomalous variation in in-situ stress measurement 48, 30, 8 hours and 37 minutes before the Wenchuan earthquake [57]; half-an-hour-scale abrupt anomaly recorded by strainmeter near to the epicenter $[5,58]$.

3.4. Possible Structure Variation. Four-year-scale preshock variation of seismic wave velocity [59]; three-year-scale [10, 60 ], one-year-scale [61], and two-to-one-month-scale variation of Earth resistivity [60, 61]; two-month-scale step-like resistivity anomalies [62]; one-month-scale increase of gas well pressures in a gas-field in Sichuan [63]; variation of noise correlation function (NCF) five days before the Wenchuan earthquake near the Longmenshan fault zone [64].

3.5. Anomalous Signals Observed in Broadband Seismic Recordings and Gravity Recordings. Decade-scale variation of gravity before the Wenchuan earthquake [65-68]; anomalous signals (tremors?) in broadband seismic recordings and gravity recordings, starting from about May 9 10, 2008 [6975].

3.6. Geomagnetic Anomalies. Geomagnetic anomalies revealed by fractional Brownian motion (fBM) analysis 2 to 3 months before the earthquake [76] and electromagnetic anomalies 2 1 months before the earthquake [77]; and anomalies 3 days before the Wenchuan earthquake, within a large range surrounding the epicenter $[78,79]$.

3.7. Ionospheric Anomalies. Ionospheric anomalies 13, 6, 5 days [80], 6 days $[11,81-83], 6 \sim 7$ days [84-86], 5 days [87-89], 8 4 days [90-93], 4 days [94], and $2 \sim 3$ days [81$83,88,94-118]$ before the Wenchuan earthquake.

3.8. Geothermal and Atmospheric Anomalies. Extreme meteorological condition 21 months and 10 months before the Wenchuan earthquake [119]; temperature variation near the epicenter since November 2007 [5]; half-year-scale decrease of precipitation [120]; temperature variation since January 2008 [121]; large-scale satellite infrared thermal anomaly, appeared since March 2008 [122]; infrared radiation anomalies about 2 months before the Wenchuan earthquake [123125]; anomalies of outgoing long-wave radiation 40 days before the Wenchuan earthquake [126]; one-month-scale decrease of the SNR of the VLF radio signal detected by satellite [127]; higher temperature in Sichuan in May, 2008, comparing to the last 30 years [128]; abnormal infrasonic waves received 10 days before the Wenchuan earthquake [11]; abnormal increase of temperature since May 5 [129]; abnormal surface latent heat flux 7 days before the earthquake [130]; abnormal variation in thermosphere 3 days before the Wenchuan earthquake [131]; "earthquake cloud" 5 hours before the earthquake [132].

Additionally, preshock macroanomalies [133-137], including animal behaviors [138, 139] and vegetation degeneration [140], are also collected and analyzed. This can act as 


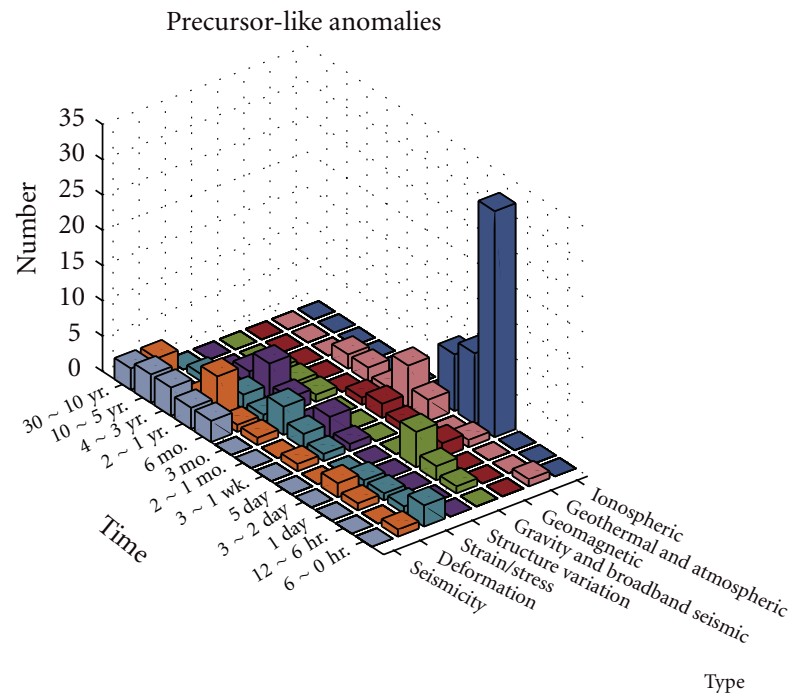

(a)

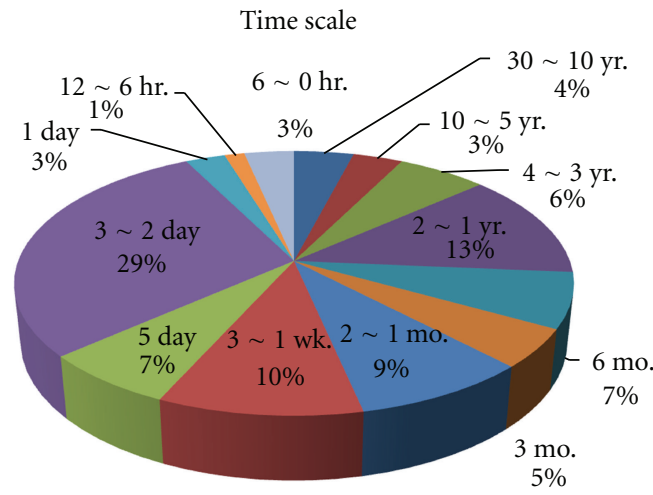

(b)

Figure 2: (a) Temporal distribution of the appearance of different types of reported anomalies, as summarized in Section 3. (b) Temporal distribution of the appearance of all the reported anomalies, as summarized in Section 3.

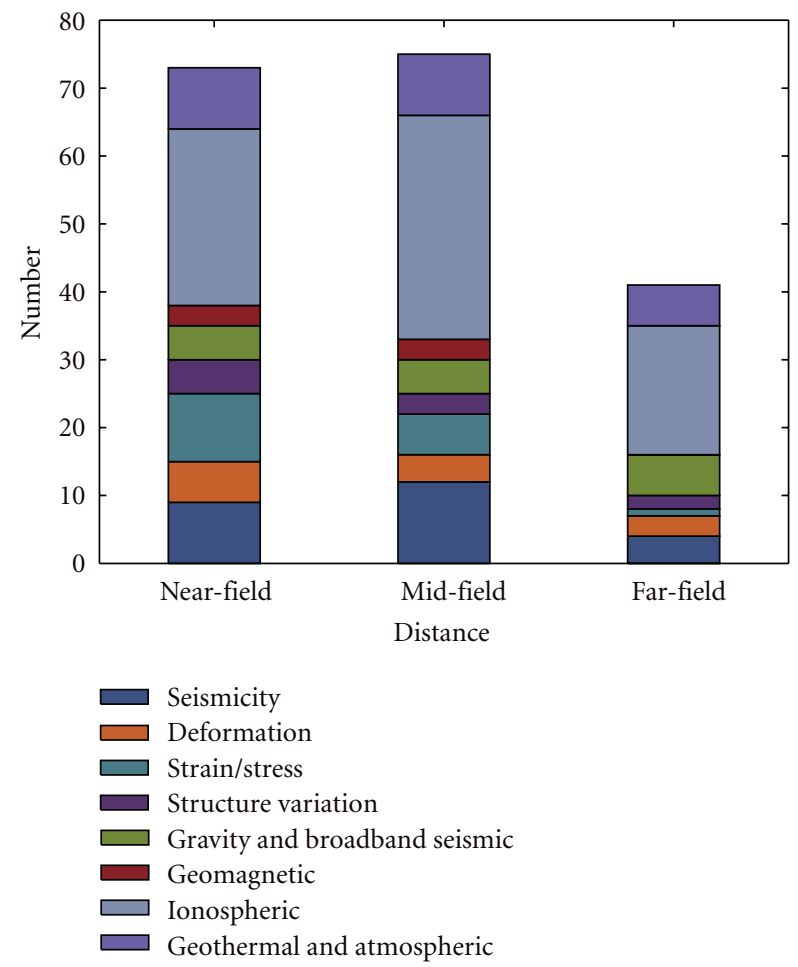

Figure 3: Distance ranges of the reported anomalies, as summarized in Section 3.

a useful reference, but how to confirm or falsify these (almost unrepeatable) observations needs further careful consideration.

At present, it is still hard to draw any definite conclusion on whether the above-mentioned observations, some are independent of others, while some are intercorrelated, may lead to a "unified description" of the earthquake preparation process. Some of the works are not understandable to us at present time regarding their methodology or observational phenomenology (e.g., [141-143]). However, it turns out that some characteristic times seem relatively important. Figure 2 shows, based on the analysis in this section, the "anomaly times" reported. It can be seen from the figure that anomalies detected by seismic, deformation, strain/stress, structure variation, gravity and broadband seismic recordings, geomagnetic, geothermal and atmospheric, and ionosphere observations appeared successively approaching the earthquake. The presently accessible data prevents from a detailed analysis of anomaly-distance dependence. As a conceptual picture, Figure 3 shows the statistics of anomalies with different distance ranges, in which "near-field" means the locations near to the earthquake fault, "mid-field" means the region within the circle centered at the epicenter and radius $1,000 \mathrm{~km}$, and "far-field" means the regions beyond this circle. For those cases with distributed anomalies (an "anomaly field", as detected by satellite TEC), we take the locations within the above three ranges, respectively, in the counting of observation reports. It can be seen that the majority of the reports are within the "near-field" and the "midfield" regions, with cautions necessary that the sampling of observational sites is by no means homogeneous.

\section{Problems in Need of Further Considerations in Future}

Except a few studies $[10,24,25,35,79,144,145]$, there are few discussions on the statistical significance of the correlation between the anomalies observed and the earthquake. This is to much extent a problem which needs to be considered seriously in future, because in the test of earthquake forecast/prediction schemes, statistical significance is one of 
the key factors in need of consideration. Without a rigorous statistical test, some of the arguments, such as the yearto-month-scale long-range low-temperature before strong earthquakes [146], seems questionable.

The role of a single station analysis is, to some extent, double sided: on one hand, there might be some "special" stations which are especially "sensitive" to some precursory anomalies, even if the anomalies are associated with remote earthquakes; on the other hand, it is hard to draw any definite conclusion only by the records of a single station, while other stations have almost no "reflections." Result of Cheng et al. [8] indicates that, despite the anomalies registered at some individual sites, the routine precursor monitoring networks had no significant anomalies recorded. In the publications, anomalies retrospectively reported at individual stations/ sites, ranging by distances from the epicenter, include abnormal strain changes observed at Guza, Sichuan, about one year before the Wenchuan earthquake [147], with epicentral distance $\sim 1.6^{\circ}$; increasing compressional stress in Wudu, Gansu, 7 months before the Wenchuan earthquake [148], and electronic anomalies in Longnan, Gansu [149]; water level variation in Guanzhong, Shaanxi [150]; deformation anomalies in Liujiaxia, Gansu [151]; water level and ground gas Hg anomalies in Zhouzhi, Shaanxi [152, 153]; ground fluid anomalies and electronic anomalies in Yunnan [154-157], with epicentral distance $~ 5.5^{\circ}$; abnormal variation of fluid temperature in Qinghai [158]; abnormal ground fluid variation at sites as far as Huangyuan, Ningxia [159]; anomalous pre-Wenchuan-earthquake deformation/ strain/stress recorded in Shanxi [160-164], with epicentral distance $\sim 10^{\circ}$; electromagnetic radiation anomaly in Gaobeidian and Ningjin, Hebei [165]; anomalous tilt in Tai'an, Shandong [166, 167]; anomalous deformation in Yixian, Hebei [168]; anomalous Earth resistivity from the end of April, 2008, in Qingdao, Shandong [169]; anomalous water level and water temperature variation 6 days before the Wenchuan earthquake, observed at Changli, Hebei [170]; anomalies of water temperature and Radon content in Ningbo, Zhejiang [171], with epicentral distance $\sim 15.6^{\circ}$. Variation of cosmic rays deals with the stations from Yangbajing, Tibet [172] to Guangzhou, Beijing, Irkutsk, Nagoya, and Moscow [173], with epicentral distance up to $\sim 51^{\circ}$. Because the Wenchuan earthquake is a great one, its preparation process may have an extremely large spatial scale. Therefore, we try not to be too skeptical about the reliability of these "remote" anomalies. However, when dealing with such a large spatial scale, and dealing with the situation that only a few sites have the anomalies, some statistical test is important.

For some of the observations, the anomalous/alarmed regions are so large that intuitive visual inspection is hard to provide correct judgments. In this case, statistical test is of special importance. An example is the ionospheric anomalies and the satellite-detected thermal anomalies as mentioned in the last section. Several days before the Wenchuan earthquake, abnormal TEC of ionosphere could be observed even in south China $[174,175]$, with distance about $11^{\circ}$, giving the idea of the size of the "warning region."
Length of data for "baseline comparison" is another concern when reading the related reports. In quite a few studies, the data for checking the "background variations" are only since 2007. This is to much extent an inevitable problem because several observational facilities are just at their beginning stage. However, this limitation prevents from getting concrete conclusions about the anomalies in the case that there is a lack of sufficient knowledge about the normal state. Evidently the continuous accumulation of observations is needed. Some of the papers mentioned objectively that there is still lack of the experiences of a great earthquake (e.g., [176]).

Coseismic changes, or changes before and after the earthquake, are presented by a few analysis (e.g., [39, 57, 81, 91, $127,147,177])$. But generally, lack of analysis on the coseismic variation seems to be one of the problems for some of the investigations. This is also a problem in need of serious consideration, since in the study of the candidate precursors, coseismic variation may provide useful constraints on the mechanism of such precursors.

Based on the above discussions, we suggest that in future works, the following issues should be paid special attention to (1) Statistical evaluation of the correlation between the anomalies reported and the earthquake needs to be considered, semiquantitatively or quantitatively if possible; (2) distance from the observation station and the "target" earthquake has to be taken into serious consideration, especially, if the distance is too large, then theoretical concepts as per the size of earthquake preparation (e.g., [178]) have to be accounted for, and statistical consideration is needed for the large-scale anomalies; (3) information about the "normal" state, or the "baseline" variations, has to be accounted for in identifying the potential anomalies; (4) comparison of preseismic, coseismic, and postseismic changes would be of help to understand the earthquake preparation process as well as the characteristics of the anomalies.

The above-mentioned "problems," however, do not imply that the publications introduced in this paper are not acceptable. As a matter of fact, all these observations are contributions to the study of the predictability of this earthquake. Especially valuable, among the publications, there are papers debating on the causes of the observed variations [179-182]. Some papers provide "negative" results [144, 183-190] which are useful in excluding the misleading information. Some papers objectively report that some of the observational systems did not show significant anomalies $[8,191]$, or that some of the observation systems are shown to be unable to capture the precursors [192, 193]. There are reports stating that among the whole set of monitoring stations, the stations with anomalies only occupy a small portion (e.g., [194]). Some works also try to exclude the effect of other factors in identifying the anomalies [195, 196]. Some of the reports (e.g., [197-206]) just provided the observation (before, or before and after the earthquake) but were too prudent to reach any direct conclusion related to earthquake precursors. Analysis tools such as ROC test [25], RTL analysis [10], and RTP [207] were used to the forecast test. If applied to geomagnetic data (e.g., [155]), then more objective conclusions about the correlation between the variation 
or fluctuation of geomagnetic field and the earthquake could be obtained. The same need exists for the tidal data (e.g., [208]), fluid data [209], electromagnetic radiation data [210], or fault deformation data [211]. Even if for "traditional" seismicity analysis (e.g., $[212,213])$, such statistical test would be of help. But generally, however, it is somehow "abnormal" that there have been not so many "alternative" explanations in such a field with so many complexities and controversies. Maybe time is a remedy to this problem.

Last but not least, very few discussions (e.g., $[214,215]$ ) are concerning how to apply the knowledge from these retrospective case studies, such as the observed patterns of seismicity, practically to the decision-making approaches to "operational earthquake forecast" [216]. Complexity of the deformation-related precursors and fluid-related precursors has caused some attentions [217-220]. Considering the observation that earthquakes occur after the restore of some of the anomalies, such as LURR [29], the anomaly-based alarm-oriented forecast problem is shown to be more complicated. Based on gravity measurement, a forward intermediate-term forecast was made [221], but the forecast did not contribute to the reduction of earthquake disasters.

\section{Discussion and Conclusions}

Systematic collection and comprehensive analysis of the cases of earthquakes regarding the precursor-like anomalies have been an academic tradition in China. In China, Earthquake Cases series have been published (in Chinese with English abstract, by the Seismological Press in Beijing) regularly since the 1970s. Contemporary level of informatics allows search and analysis of different data flow including scientific publications themselves. In the case of Wenchuan, what can be seen is that different observations may have some intrinsic consistency to each other, providing heuristic clues to the preparation process of this great earthquake. Remarkably, several characteristic times, such as $2 \sim 4$ days and $1 \sim 2$ years, may reveal the preparation and approaching process of this inland great earthquake, which is in need of further investigation.

In the study on earthquake forecast/prediction, it is always much easier and much simpler to be critical or skeptical than to conduct concrete observations. Keeping this in mind, the objective of this paper is firstly to summarize what have been done either in China or in other places of the world; secondly to introduce these works, especially to non-Chinese-speaking communities; thirdly to avoid being too demanding or too skeptical in commenting on these works; and at last to propose, in a constructive way, several problems in need of consideration in future-some of them are not complicated but important. We believe that, if these problems were paid special attention to, then to much extent, more useful conclusions would be obtained, and the study on earthquake forecast/prediction would be "accelerated". And this hint is important not only for China but also for other places all over the world.

Being only 3 years after the Wenchuan earthquake, at the present time this work is still far from the stage of systematic evaluation [222-224] and/or empirical semiquantitative analysis [225-228]. More concrete conclusions need more time, although we have had an apparently good start with pretty rich (but complicated) materials.

\section{Acknowledgments}

Thanks to Professor R. Console for invitation to this special issue and patience to tolerate the delay in submission. Discussion with Harsh Gupta, V. Kossobokov, Jie Liu, Xiangchu Yin, and Yongxian Zhang stimulated and improved this investigation. Changsheng Jiang, Hanshu Peng, and Jiancang Zhuang helped in the work. Thanks are due to the staffs of the National Library of China, Beijing, for valuable advice and assistance in accessing to the databases. This work is supported by the WFSD project.

\section{References}

[1] Y. Chen and D. C. Booth, The Wenchuan Earthquake of 2008, Science Press, Springer, Beijing, China, 2011.

[2] A. M. Cetto, Scientific journal publishing in the developing world? ICSU-COSTED Occasional Paper No.3, 1998.

[3] Q. F. Chen and K. L. Wang, "The 2008 Wenchuan earthquake and earthquake prediction in China," Bulletin of the Seismological Society of America, vol. 100, no. 5, pp. 2840-2857, 2010.

[4] Y.-T. Che, C.-L. Liu, J.-Z. Yu, Z.-J. Guan, and J. Li, "Underground fluid anomaly and macro anomaly of Ms 8.0 Wenchuan earthquake and opinions about earthquake prediction," Seismology and Geology, vol. 30, no. 4, pp. 828-838, 2008 (Chinese).

[5] Z. X. Ouyang, H. X. Zhang, Z. Z. Fu, B. Gou, and W. L. Jiang, "Abnormal phenomena recorded by several earthquake precursor observation instruments before the Ms8.0 Wenchuan, Sichuan earthquake," Acta Geologica Sinica, vol. 83, no. 4, pp. 834-844, 2009.

[6] R. Yan, "Analysis of earthquake precursor monitoring data," in Research Report on the Wenchuan M8.0 Earthquake, Monitoring and Forecasting Department of China Earthquake Administration, Ed., chapter 6, pp. 170-193, Seismological Press, Beijing, China, 2009 (Chinese).

[7] X.-M. Zhang, J.-H. Ding, X.-H. Shen et al., "Electromagnetic perturbations before Wenchuan M8 earthquake and stereo electromagnetic observation system," Chinese Journal of Radio Science, vol. 24, no. 1, pp. 1-8, 2009 (Chinese).

[8] W. Z. Cheng, Z. J. Guan, Q. Su, X. Ruan, and Z. W. Zhang, "Precursory anomalies in Sichuan region before 2008 Wenchuan Ms8.0 earthquake and their statistical analysis," Acta Seismologica Sinica, vol. 33, no. 3, pp. 304-318, 2011 (Chinese).

[9] Q. Huang, "Seismicity changes prior to the Ms8.0 Wenchuan earthquake in Sichuan, China," Geophysical Research Letters, vol. 35, no. 23, Article ID L23308, 2008.

[10] Q. H. Huang, "Retrospective investigation of geophysical data possibly associated with the Ms8.0 Wenchuan earthquake in Sichuan, China," Journal of Asian Earth Sciences, vol. 41, no. 4-5, pp. 421-427, 2010.

[11] C. Y. Liu, J. Y. Liu, W. S. Chen, J. Z. Li, Y. Q. Xia, and X. Y. Cui, "An integrated study of anomalies observed before four major earthquakes: 2004 Sumatra M9.3, 2006 Pingtung M7.0, 2007 Chuetsu Oki M6.8, and 2008 Wenchuan M8.0," Journal of Asian Earth Sciences, vol. 41, no. 4-5, pp. 401-409, 2010. 
[12] L. Wu, "Misconception analysis and suggestions for earthquake monitoring and predication," Science \& Technology Review, vol. 26, no. 10, pp. 28-29, 2008 (Chinese).

[13] J. Liu, T. Guo, L. Yang, Y. Su, and G. Li, "Retrospection on the conclusions of earthquake tendency forecast before the Wenchuan Ms8.0 earthquake," Earthquake Research in China, vol. 23, no. 2, pp. 119-133, 2009.

[14] Z. C. Zhang and W. Zhang, "Some reflections on the 12 May, 2008 Wenchuan earthquake," Earthquake, vol. 29, no. 1, pp. 193-202, 2009 (Chinese).

[15] W. Zhao, "Pondering over the scientific thinking of earthquake prediction from the miss report of Wenchuan earthquake-re-discussing Li Siguang's earthquake prediction thought," Engineering Science, vol. 11, no. 6, pp. 4-15, 2009 (Chinese).

[16] The Seismological Society of China, Ed., "Proceedings of the 12th Assembly of the Seismological Society of China," Recent Development in World Seismology, no. 11, pp. 1-172, 2008 (Chinese).

[17] The Seismological Society of China, Ed., "Earthquake Prediction Development Forum Paper Abstract Special Collection," Recent Development in World Seismology, no. 4, pp. 1-103, 2009 (Chinese).

[18] The Seismological Society of China, Ed., "Abstracts from Cross-Strait Seminar on Wenchuan Earthquake," Recent Development in World Seismology, no. 6, pp. 1-24, 2010 (Chinese).

[19] P. Zhang, Q. Deng, G. Zhang et al., "Active tectonic blocks and strong earthquakes in the continent of China," Science in China D, vol. 46, supplement 2, pp. 13-24, 2003.

[20] L.-X. Gao, J.-L. Sun, and H. Zhang, "Moderate-to-strong earthquake quiescence is the most significant seismic anomaly before the Wenchuan 8.0 earthquake," Earthquake, vol. 30, no. 1, pp. 90-97, 2010 (Chinese).

[21] C. S. Jiang and Z. L. Wu, "Seismic moment release before the May 12, 2008, Wenchuan earthquake in Sichuan of southwest China," Concurrency Computation Practice and Experience, vol. 22, no. 12, pp. 1784-1795, 2010.

[22] X.-Z. Chen, X.-Y. Guo, and Y.-E. Li, "Distribution characteristics of the month-scale number for earthquakes occurred on the Longmenshan fault," Earthquake, vol. 30, no. 2, pp. 20-28, 2010 (Chinese).

[23] Y. Xue, J. Liu, S. Mei, and Z. Song, "Characteristics of seismic activity before the Ms8.0 Wenchuan earthquake," Earthquake Science, vol. 22, no. 5, pp. 519-529, 2009.

[24] C. Jiang, Z. Wu, H. Ma, and L. Zhou, "Sichuan-Yunnan versus Andaman-Sumatra: PI approach and retrospective forecast test," Acta Seismologica Sinica, vol. 31, no. 3, pp. 307-318, 2009 (Chinese).

[25] C. S. Jiang and Z. L. Wu, "PI forecast for the Sichuan-Yunnan region: retrospective test after the May 12, 2008, Wenchuan earthquake," Pure and Applied Geophysics, vol. 167, no. 6-7, pp. 751-761, 2010.

[26] L. Zou and X. Wang, "Study on the characteristics of the medium-depth seismicity before the Kunlun Mountain earthquake and the Wenchuan earthquake," Seismological and Geomagnetic Observation and Research, vol. 31, no. 5, pp. 37-44, 2010 (Chinese).

[27] Y. Su and J. Liu, "Quiescence anomalies of $M \geq 6.0$ earthquakes before the 2008 Wenchuan (M8.0) earthquake in Sichuan-Yunnan region," Journal of Seismological Research, vol. 33, no. 2, pp. 119-124, 2010 (Chinese).

[28] H.-B. Zhu, "The similar evolution of seismicity patterns of strong-moderate earthquakes before about Ms8 earthquakes of Qinghai-Tibet block," Chinese Journal of Geophysics, vol. 53, no. 7, pp. 1611-1621, 2010 (Chinese).

[29] X.-C. Yin, L.-P. Zhang, Y.-X. Zhang et al., "Large scale LURR anomaly before Wenchuan earthquake," Earthquake, vol. 29, no. 1, pp. 53-59, 2009 (Chinese).

[30] H. Yu, J. Cheng, and Y. Wan, "Load/unload response ratio and stress accumulation model before large earthquakes," Acta Seismologica Sinica, vol. 32, no. 5, pp. 517-528, 2010 (Chinese).

[31] C. Wang, J. Cao, H. Guo, L. Zhang, and N. Xue, "Short-term earthquake prediction in the region of Sichuan-Yunnan using method of modulated earthquake," Earthquake Research in China, vol. 26, no. 2, pp. 210-217, 2010 (Chinese).

[32] P. Lu, X. Zhao, Z. Cui, X. Liu, and Y. Duan, "Space-time evolution characteristics of seismic inhomogeneous degree before Wenchuan earthquake," Journal of Institute of DisasterPrevention Science and Technology, vol. 10, no. 3, pp. 126-130, 2008 (Chinese).

[33] Z. Xie, Y. Zhu, X. Lei, and Z. Song, "Variation of multiple seismicity parameters used to investigate critical behavior of the Wenchuan earthquake preparation," Acta Seismologica Sinica, vol. 32, no. 6, pp. 659-669, 2010 (Chinese).

[34] G. Luo, M. Yang, H. Ma, and X. Xu, "Intermediate and shorttrem anomalies of seismic activity energy field before the Wenchuan M8.0 earthquake," Earthquake, vol. 31, no. 3, pp. 135-142, 2011 (Chinese).

[35] H. C. Li and C. C. Chen, "Characteristics of long-term regional seismicity before the 2008 Wen-Chuan, China, earthquake using pattern informatics and genetic algorithms," Natural Hazards and Earth System Sciences, vol. 11, no. 3, pp. 1003-1009, 2011.

[36] S. Zhao, S. Xu, P. Wu, and L. Ma, "Earthquake occurrence correlated with the movement of the Sun and the Moon," Science \& Technology Review, vol. 29, no. 13, pp. 18-23, 2011 (Chinese).

[37] H. Wang, X. Zhao, Y. Li, and X. Chen, "A study on the relationships between Earth rotation and the occurrences of several strong earthquakes," Earthquake, vol. 31, no. 2, pp. 33-41, 2011 (Chinese).

[38] F. Du, X.-Z. Wen, P.-Z. Zhang, and Q.-L. Wang, "Interseismic deformation across the Longmenshan fault zone before the 2008 M8.0 Wenchuan earthquake," Chinese Journal of Geophysics, vol. 52, no. 11, pp. 2729-2738, 2009 (Chinese).

[39] G. Gu, W. Wang, G. Meng, and Y. Xu, "Crustal movements before and after the Wenchuan earthquake as detected by GPS observations," Geomatics and Information Science of Wuhan University, vol. 34, no. 11, pp. 1336-1339, 2009 (Chinese).

[40] G. Gu, G. Meng, and Y. Fang, "Crustal movement in the earthquake area before and after 2008 Wenchuan earthquake as detected by precise single epoch positioning of GPS observations," Acta Seismologica Sinica, vol. 33, no. 3, pp. 319-326, 2011 (Chinese).

[41] C. Zhang, H. Shao, C. Shi, and J. Chen, "Research on surface variation characteristics of ground tilt in Longmenshan fault zone before Wenchuan Ms8.0 earthquake," Journal of Geodesy and Geodynamics, vol. 31, supplement, pp. 6-9, 2011 (Chinese).

[42] Q. Jiao, X. Yang, L. Xu, and B. Wang, "Preliminary study on motion characteristics of Longmenshan fault before and after Ms8.0 Wenchuan earthquake," Journal of Geodesy and Geodynamics, vol. 28, no. 4, pp. 7-11, 2008 (Chinese).

[43] L. Guo, L. Ta, D. Sun, and X. Du, "Vertical deformation characteristic of Longmenshan fault zone before Wenchuan 
Ms8.0 earthquake," South China Journal of Seismology, vol. 29, no. 3, pp. 1-8, 2009 (Chinese).

[44] Y. Fang, Z. Jiang, and G. Gu, "Oscillation analysis of GPS horizontal time series before the Wenchuan earthquake," Journal of Seismological Research, vol. 33, no. 2, pp. 125-130, 2010 (Chinese).

[45] L. Guo, X. Hu, F. Zhang, C. Chen, and D. Sun, "Baseline variation of GPS continuous sites and current activity of Qinghai-Tibet block," Journal of Geodesy and Geodynamics, vol. 29, no. 4, pp. 10-14, 2009 (Chinese).

[46] Y. Zhang and Y. Wu, "Anomaly of fixed deformation data and explain before the 2008 Wenchuan earthquake," Geomatics and Information Science of Wuhan University, vol. 35, no. 1, pp. 25-29, 2010 (Chinese).

[47] C. Ke, Z. Li, and M. Dou, "Anomalous response of crust tilt tidal factor $\gamma$ value in Shanxi before Wenchuan Ms8.0 earthquake," Journal of Geodesy and Geodynamics, vol. 28, no. 6, pp. 56-60, 2008 (Chinese).

[48] Y. Jing, H. Zhang, Y. Sun, H. Li, L. Fan, and Y. Xiong, "Abnormal changes of crustal deformation before Wenchuan 8.0 earthquake observed by BSQ model digital tilt meter," Geological Journal of China Universities, vol. 15, no. 3, pp. 358-364, 2009 (Chinese).

[49] W. Cheng, X. Ruan, H. Qiao, Z. Zhang, and J. Yong, "Research on the dynamic change of regional stress fields before the Ms8.0 Wenchuan earthquake," Earthquake Research in China, vol. 23, no. 3, pp. 244-256, 2009.

[50] Z. S. Jiang, Y. Wu, Y. Fang, P. Li, and W. Wang, "The dynamic characteristics of strain fields and crustal movement before the Wenchuan earthquake (Ms=8.0)," Earthquake, vol. 23, no. 3, pp. 257-265, 2009.

[51] G. Fan and Q. Jiao, "Analysis of fault activity characteristics in Sichuan-Yunnan area before Wenchuan Ms8.0 earthquake," Journal of Geodesy and Geodynamics, vol. 28, no. 6, pp. 2730, 2008 (Chinese).

[52] T. Chen, "Seismic rate and small seismic swarm changes before the 2008 Wenchuan M8.0 earthquake," Earthquake Research in Sichuan, no. 3, pp. 23-29, 2010 (Chinese).

[53] J. Zhang and Q. Liu, "Processing and analysis of fourcomponent borehole strain observations," Journal of Geodesy and Geodynamics, vol. 30, no. 6, pp. 6-9, 2010 (Chinese).

[54] G.-L. Diao, X.-W. Xu, Y. Chen et al., "The precursory significance of tectonic stress field transformation before the Wenchuan Mw7.9 earthquake and the Chi-Chi Mw7.6 earthquake," Chinese Journal of Geophysics, vol. 54, no. 1, pp. 128136, 2011 (Chinese).

[55] Y. Zhang, Y. Wu, and P. Lv, "Characteristics of deformation anomaly obtained from tilt and strain observations before the Wenchuan Ms8.0 earthquake," Acta Seismologica Sinica, vol. 31, no. 2, pp. 152-159, 2009 (Chinese).

[56] Q.-L. Guo, C.-H. Wang, H.-S. Ma, and C.-G. Wang, "In-situ hydro-fracture stress measurement before and after the Wenchuan Ms8.0 earthquake of China," Chinese Journal of Geophysics, vol. 52, no. 5, pp. 1395-1401, 2009 (Chinese).

[57] H. Peng, X. M. Ma, and J. J. Jiang, "Process analysis of in-situ strain during the Ms8.0 Wenchuan earthquake — data from the stress monitoring station at Shandan," Acta Geologica Sinica, vol. 83, no. 4, pp. 754-766, 2009.

[58] A. Niu, L. Zhan, W. Yan, and P. Ji, "Borehole strain measurement and application to earthquake prediction in China," Journal of Geodesy and Geodynamics, vol. 31, no. 2, pp. 4852, 2011 (Chinese).

[59] L. Wang, Y. Li, F. Li et al., "Temporal variation of Vp/Vs, Vp and Vs before and after 2008 Wenchuan earthquake," Acta Seismologica Sinica, vol. 33, no. 1, pp. 1-14, 2011 (Chinese).
[60] X. B. Du, "Two types of changes in apparent resistivity in earthquake prediction," Science China Earth Sciences, vol. 54, no. 1, pp. 145-156, 2011.

[61] W. Xiao and H. Guan, "Anomalous change features of resistivity before the Wenchuan M8.0 earthquake and other large earthquake in China," Northwestern Seismological Journal, vol. 31, no. 4, pp. 349-354, 2009 (Chinese).

[62] X.-M. Zhang, M. Li, and H.-P. Guan, "Anomaly analysis of earth resistivity observations before the Wenchuan earthquake," Earthquake, vol. 29, no. 1, pp. 108-115, 2009 (Chinese).

[63] M. Yang, D. Chen, Y. Huang, and H. Gong, "Abnormal gas well pressure of Zhongba gas field, Sichuan, before and after the Wenchuan earthquake," Acta Seismologica Sinica, vol. 33, no. 4, pp. 505-514, 2011 (Chinese).

[64] H. S. Peng, Z. L. Wu, and C. S. Jiang, "Pre-seismic changes of noise correlation function (NCF) before the Wenchuan earthquake?" Concurrency Computation Practice and Experience, vol. 22, no. 12, pp. 1774-1783, 2010.

[65] Y. Zhu, W. Liang, Y. Xu, S. Guo, and F. Liu, "Dynamic variation of gravity field before and after Wenchuan Ms8.0 earthquake," Acta Seismologica Sinica, vol. 32, no. 6, pp. 633640, 2010 (Chinese).

[66] Y. Q. Zhu, F. B. Zhan, J. C. Zhou, W. F. Liang, and Y. M. Xu, "Gravity measurements and their variations before the 2008 Wenchuan earthquake," Bulletin of the Seismological Society of America B, vol. 100, no. 5, pp. 2815-2824, 2010.

[67] Y. Zhu, F. Liu, and S. Guo, "Temporal variation of gravity field before and after Wenchuan Ms8.0 earthquake," Geodesy and Geodynamics, vol. 2, no. 2, pp. 33-38, 2011.

[68] Y. Zhu, F. Liu, W. Liang, and Y. Xu, "Gravity variation associated with Wenchuan earthquake in western Sichuan," Geodesy and Geodynamics, vol. 2, no. 1, pp. 55-60, 2011.

[69] X. Hao, X. Hu, H. Xu et al., "Gravity disturbance before Wenchuan Ms8.0 earthquake," Journal of Geodesy and Geodynamics, vol. 28, no. 3, pp. 129-131, 2008 (Chinese).

[70] X. Hao and X. Hu, "Disturbance before the Wenchuan earthquake detected by broadband seismometer," Progress in Geophysics, vol. 23, no. 4, pp. 1332-1335, 2008 (Chinese).

[71] X. Hao and X. Hu, "Are "third microseisms" in anomalous tremor before the great Wenchuan earthquake?" Progress in Geophysics, vol. 24, no. 4, pp. 1213-1215, 2009 (Chinese).

[72] L. Yang, "Preliminary study on the tremors with special frequency recorded by seismograph before Wenchuan earthquake and its charaters," Recent Developments in World Seismology, no. 1, pp. 14-19, 2009 (Chinese).

[73] L. Yang, J. Wang, J. Feng, Y. Hu, J. Chen, and J. Yao, "Preliminary study and application on the tremors with lower frequency recorded by seismograph before the Wenchuan earthquake," Earthquake Research in China, vol. 25, no. 4, pp. 356-366, 2009 (Chinese).

[74] L. Yin and L. Yang, "Research on low-frequency wave of the broadband digital data and the information of shortimminent precursor before strong earthquakes," Northwestern Seismological Journal, vol. 32, no. 1, pp. 82-87, 2010 (Chinese).

[75] Y. Zhang, Y. Wu, Y. Lv, J. Hu, and P. Lu, "Anomalies observed by ultra broadband seismometer before Wenchuan earthquake," Journal of Geodesy and Geodynamics, vol. 31, no. 1, pp. 15-18, 2011 (Chinese).

[76] M. Li, J. Lu, X. Su, and Z. Feng, "A study on fractal Brownian motion of geomagnetic observations before large earthquakes," Acta Seismologica Sinica, vol. 31, no. 6, pp. 650-659, 2009 (Chinese). 
[77] Y.-Y. Fan, X.-B. Du, J. Zlotnicki et al., "The electromagnetic phenomena before the Ms8.0 Wenchuan earthquake," Chinese Journal of Geophysics, vol. 53, no. 12, pp. 2887-2898, 2010 (Chinese).

[78] J. Hu, W. Liu, M. Guo, and H. Zheng, “"Double low-points” anomaly in daily variation of vertical component of geomagnetic field before the Ms8.0 Wenchuan earthquake," Earthquake Science, vol. 22, no. 5, pp. 539-543, 2009.

[79] W. Wang, J. Ding, S. Yu, and Y. Zhang, "Short-term and imminent geomagnetic anomalies of the Wenchuan Ms8.0 earthquake and exploration on earthquake forecast," Earthquake Science, vol. 22, no. 2, pp. 135-141, 2009.

[80] H. K. Jhuang, Y. Y. Ho, Y. Kakinami et al., "Seismo-ionospheric anomalies of the GPS-TEC appear before the 12 May 2008 magnitude 8.0 Wenchuan earthquake," International Journal of Remote Sensing, vol. 31, no. 13, pp. 3579-3587, 2010.

[81] X. Zhang, X. Hu, and C. Zhang, "Ionospheric response with Wenchuan big earthquake by occulted data," GNSS World of China, no. 5, pp. 1-5, 2008 (Chinese).

[82] J. Blecki, M. Parrot, and R. Wronowski, "Studies of the electromagnetic field variations in ELF frequency range registered by DEMETER over the Sichuan region prior to the 12 May 2008 earthquake," International Journal of Remote Sensing, vol. 31, no. 13, pp. 3615-3629, 2010.

[83] Y. Y. Zhou, Y. Wu, X. J. Qiao, F. Y. Zhu, and J. Yang, "Anomalous variations of ionospheric VTEC before Ms8.0 Wenchuan earthquake," Chinese Journal of Geophysics, vol. 53, no. 3, pp. 556-566, 2010, (with Chinese abstract).

[84] X.-M. Zhang, X.-H. Shen, X.-Y. Ouyang et al., "Ionosphere VLF electric field anomalies before Wenchuan M8 earthquake," Chinese Journal of Radio Science, vol. 24, no. 6, pp. 1024-1032, 2009 (Chinese).

[85] H. Yu, H. Zhou, and X. Qiao, "Study on wave propagation of ELF emission anomaly before Ms8.0 Wenchuan earthquake," Acta Seismologica Sinica, vol. 32, no. 6, pp. 641-648, 2010 (Chinese).

[86] Z. An, Y. Fan, J. Liu et al., "Analysis on ion temperature variation detected by DEMETER before 2008 Wenchuan Ms8.0 earthquake," Acta Seismologica Sinica, vol. 32, no. 6, pp. 754 759, 2010 (Chinese).

[87] C. C. Hsiao, J. Y. Liu, K. I. Oyama et al., "Seismo-ionospheric precursor of the $2008 \mathrm{Mw} 7.9$ Wenchuan earthquake observed by FORMOSAT-3/COSMIC," GPS Solutions, vol. 14, no. 1, pp. 83-89, 2009.

[88] Z. Nie, F. Zhu, and N. Fu, "Application of Kalman filtering in detecting ionospheric TEC anomaly prior to earthquake," Journal of Geodesy and Geodynamics, vol. 31, no. 3, pp. 47-50, 2011 (Chinese).

[89] J. Xiong, Y. Wu, Y. Zhou, and J. Lin, "Ionospheric anomalies detected before 2008 Wenchuan earthquake," Journal of Geodesy and Geodynamics, vol. 31, no. 2, pp. 28-31, 2011 (Chinese).

[90] J. Lin, Y. Wu, and F. Zhu, "Ionosphere TEC anomalous disturbance of pre-seism," Geomatics and Information Science of Wuhan University, vol. 34, no. 8, pp. 975-978, 2009 (Chinese).

[91] S. Sarkar and A. K. Gwal, "Satellite monitoring of anomalous effects in the ionosphere related to the great Wenchuan earthquake of May 12, 2008," Natural Hazards, vol. 55, no. 2, pp. 321-332, 2010.

[92] J. Xiong, Y. Wu, F. Zhu, J. Lin, Y. Zhou, and J. Yang, “Anomalous disturbance of ionospheric NmF2 during Wenchuan earthquake," Journal of Geodesy and Geodynamics, vol. 28, no. 6, pp. 22-26, 2008 (Chinese).
[93] F. Zhu, Y. Wu, J. Lin, Y. Zhou, J. Xiong, and J. Yang, "Study on ionospheric TEC anomaly prior to Wenchuan Ms8.0 earthquake," Journal of Geodesy and Geodynamics, vol. 28, no. 6, pp. 16-21, 2008 (Chinese).

[94] J. W. Lin, "Two-dimensional ionospheric total electron content map (TEC) seismo-ionospheric anomalies through image processing using principal component analysis," Advances in Space Research, vol. 45, no. 11, pp. 1301-1310, 2010.

[95] B. Zhao, W. Wan, M. Wang, L. Liu, and B. Ning, "Recent advances on the ionospheric pre-cursors of earthquakes and ionospheric variations prior to Wenchuan earthquake," Science \& Technology Review, vol. 26, no. 11, pp. 30-34, 2008 (Chinese).

[96] J. Li, G. Meng, M. Wang, H. Liao, and X. Shen, "Investigation of ionospheric TEC changes related to the 2008 Wenchuan earthquake based on statistic analysis and signal detection," Earthquake Science, vol. 22, no. 5, pp. 545-553, 2009.

[97] J. Y. Liu, Y. I. Chen, C. H. Chen et al., "Seismoionospheric GPS total electron content anomalies observed before the 12 May 2008 Mw7.9 Wenchuan earthquake," Journal of Geophysical Research A, vol. 114, no. 4, Article ID A04320, 2009.

[98] T. G. Yu, T. Mao, Y. G. Wang, and J. S. Wang, "Study of the ionospheric anomaly before the Wenchuan earthquake," Chinese Science Bulletin, vol. 54, no. 6, pp. 1080-1086, 2009.

[99] Z.-C. Zeng, B. Zhang, G.-Y. Fang, D.-F. Wang, and H.-J. Yin, "The analysis of ionospheric variations before Wenchuan earthquake with DEMETER data," Chinese Journal of Geophysics, vol. 52, no. 1, pp. 11-19, 2009 (Chinese).

[100] X. Zhang, X. Shen, J. Liu, X. Ouyang, J. Qian, and S. Zhao, "Analysis of ionospheric plasma perturbations before Wenchuan earthquake," Natural Hazards and Earth System Science, vol. 9, no. 4, pp. 1259-1266, 2009.

[101] Y. Y. Zhou, Y. Wu, X. J. Qiao, and X. X. Zhang, "Ionospheric anomalies detected by ground-based GPS before the Mw7.9 Wenchuan earthquake of May 12, 2008, China," Journal of Atmospheric and Solar-Terrestrial Physics, vol. 71, no. 8-9, pp. 959-966, 2009.

[102] F. Zhu, Y. Wu, J. Lin, Y. Zhou, J. Xiong, and J. Yang, "Study on method of detecting ionospheric TEC anomaly before earthquake," Journal of Geodesy and Geodynamics, vol. 29, no. 3, pp. 50-54, 2009 (Chinese).

[103] F. Zhu, Y. Wu, J. Lin, Y. Zhou, J. Xiong, and J. Yang, "Anomalous response of ionospheric VTEC before the Wenchuan earthquake," Acta Seismologica Sinica, vol. 31, no. 2, pp. 180187, 2009 (Chinese).

[104] Z.-H. Ding, J. Wu, S.-J. Sun, J.-S. Chen, and P.-P. Ban, “The variation of ionosphere on some days before the Wenchuan earthquake," Chinese Journal of Geophysics, vol. 53, no. 1, pp. 30-38, 2010 (Chinese).

[105] Y. Kakinami, J. Y. Liu, L. C. Tsai, and K. I. Oyama, "Ionospheric electron content anomalies detected by a FORMOSAT-3/COSMIC empirical model before and after the Wenchuan earthquake," International Journal of Remote Sensing, vol. 31, no. 13, pp. 3571-3578, 2010.

[106] S. A. Pulinets, V. G. Bondur, M. N. Tsidilina, and M. V. Gaponova, "Verification of the concept of seismoionospheric coupling under quiet heliogeomagnetic conditions, using the Wenchuan (China) earthquake of May 12, 2008, as an example," Geomagnetism and Aeronomy, vol. 50, no. 2, pp. 231-242, 2010.

[107] T. Xu, Y. Hu, J. Wu, Z. Wu, Y. Suo, and J. Feng, "Giant disturbance in the ionospheric F2 region prior to the M8.0 Wenchuan earthquake on 12 May 2008," Annales Geophysicae, vol. 28, no. 8, pp. 1533-1538, 2010. 
[108] X. M. Zhang, X. H. Shen, J. Liu, X. Y. Ouyang, J. D. Qian, and S. F. Zhao, "Ionospheric perturbations of electron density before the Wenchuan earthquake," International Journal of Remote Sensing, vol. 31, no. 13, pp. 3559-3569, 2010.

[109] B. Q. Zhao, M. Wang, T. Yu, G. R. Xu, W. X. Wan, and L. B. Liu, "Ionospheric total electron content variations prior to the 2008 Wenchuan earthquake," International Journal of Remote Sensing, vol. 31, no. 13, pp. 3545-3557, 2010.

[110] Y. Zhao, X. Zhang, and J. Liu, "Perturbation analysis of the ionospheric TEC before and after the Wenchuan earthquake," Progress in Geophysics, vol. 25, no. 2, pp. 447-453, 2010 (Chinese).

[111] F. Zhu, Y. Wu, J. Lin, and Y. Zhou, “Temporal and spatial characteristics of VTEC anomalies before Wenchuan Ms8.0 earthquake," Geodesy and Geodynamics, vol. 1, no. 1, pp. 2328, 2010.

[112] F. Zhu, Y. Wu, and N. Fu, "Application of Kalman filter in detecting pre-earthquake ionospheric TEC anomaly," Geodesy and Geodynamics, vol. 2, no. 2, pp. 43-47, 2011.

[113] M. V. Klimenko, V. V. Klimenko, I. E. Zakharenkova, S. A. Pulinets, B. Zhao, and M. N. Tsidilina, "Formation mechanism of great positive TEC disturbances prior to Wenchuan earthquake on May 12, 2008," Advances in Space Research, vol. 48, no. 3, pp. 488-499, 2011.

[114] J. W. Lin, "Use of principal component analysis in the identification of the spatial pattern of an ionospheric total electron content anomalies after China's May 12, 2008, M = 7.9 Wenchuan earthquake," Advances in Space Research, vol. 47, no. 11, pp. 1983-1989, 2011.

[115] Y. Wu, N. Fu, J. Lin et al., "Research on TEC anomalies before Ms8.0 Wenchuan earthquake by using Kalman filtering," Journal of Geodesy and Geodynamics, vol. 31, no. 2, pp. 2327, 2011 (Chinese).

[116] T. Xu, Y. L. Hu, J. A. Wu et al., "Anomalous enhancement of electric field derived from ionosonde data before the great Wenchuan earthquake," Advances in Space Research, vol. 47, no. 6, pp. 1001-1005, 2011.

[117] T. Xu, J. Wu, Z. Zhao et al., "Monitoring ionospheric variations before earthquakes using the vertical and oblique sounding network over China," Natural Hazards and Earth System Sciences, vol. 11, no. 4, pp. 1083-1089, 2011.

[118] J. Yang, Y. Wu, and Y. Zhou, "Probe into seismo-ionospheric anomaly of Wenchuan Ms8.0 earthquake based on computerized ionospheric tomography," Journal of Geodesy and Geodynamics, vol. 31, no. 1, pp. 9-14, 2011 (Chinese).

[119] L. Li, J. Yang, J. Huang, and Q. Wu, "Analysis about the specific background of rare drought and intense heat and great floodwater which should not be ignored before Wenchuan earthquake," Plateau Earthquake Research, vol. 20, no. 4, pp. 69-75, 2008 (Chinese).

[120] X. Jiang and Y. Li, "The statistical analysis of earthquake and precipitation in Sichuan Province," Plateau and Mountain Meteorology Research, vol. 28, no. 2, pp. 33-36, 2008 (Chinese).

[121] J. Li and S. Liu, "On the anomalies of crustal deformation \& surface temperature and its correlation: a case study of Wenchuan earthquake," Geography and Geo-Information Science, vol. 25, no. 1, pp. 79-83, 2009 (Chinese).

[122] L. J. Wei, J. F. Guo, J. H. Lu, Z. Q. Lu, H. B. Li, and H. Cai, "Satellite thermal infrared earthquake precursor to the Wenchuan Ms8.0 earthquake in Sichuan, China, and its analysis on geo-dynamics," Acta Geologica Sinica, vol. 83, no. 4, pp. 767-775, 2009.
[123] L. Wei, J. Guo, H. Cai, H. Li, and Z. J. John, "Satellite thermal infrared anomaly: a short-term and impending earthquake precursor before the Wenchuan Ms8.0 earthquake in Sichuan, China," Acta Geoscientica Sinica, vol. 29, no. 5, pp. 583-591, 2008 (Chinese).

[124] X. Guo, Y. Zhang, M. Zhong, W. Shen, and C. Wei, "Variation characteristics of OLR for the Wenchuan earthquake," Chinese Journal Geophysics, vol. 53, no. 6, pp. 980-988, 2010.

[125] Y. S. Zhang, X. A. Guo, M. J. Zhong, W. R. Shen, W. Li, and B. $\mathrm{He}$, "Wenchuan earthquake: brightness temperature changes from satellite infrared information," Chinese Science Bulletin, vol. 55, no. 18, pp. 1917-1924, 2010.

[126] F. Jing, X.-H. Shen, C.-L. Kang, Q.-Y. Meng, and P. Xiong, "Anomalies of outgoing longwave radiation before some medium to large earthquakes," Earthquake, vol. 29, no. 4, pp. 117-122, 2009 (Chinese).

[127] Y. F. He, D. M. Yang, H. R. Chen, J. D. Qian, R. Zhu, and M. Parrot, "SNR changes of VLF radio signals detected onboard the DEMETER satellite and their possible relationship to the Wenchuan earthquake," Science in China D, vol. 52, no. 6, pp. 754-763, 2009.

[128] W. Min and X. Xu, "Primary analysis of the variation of surface air temperature before and after Wenchuan earthquake," Plateau and Mountain Meteorology Research, vol. 28, no. 2, pp. 42-46, 2008 (Chinese).

[129] W. Ma, "Abnormal phenomenon of NCEP before Wenchuan earthquake," Science \& Technology Review, vol. 26, no. 10, pp. 37-39, 2008 (Chinese).

[130] M. Li, C. Kang, Z. Li, F. Jing, Y. Xue, and W. Yan, "Abnormal surface latent heat flux prior to the Wenchuan Ms8.0 earthquake," Earthquake, vol. 30, no. 3, pp. 64-71, 2010 (Chinese).

[131] H. Zeng, G. Zhu, G. Qin, H. Chen, and Y. Li, "Abnormal variation of thermosphere atmospheric density during the period of big earthquake," Chinese Journal of Space Science, vol. 31, no. 3, pp. 318-322, 2011 (Chinese).

[132] L. Wu, S. Liu, Y. Chen, B. Ma, and L. Li, "Satellite thermal infrared and cloud abnormities before Wenchuan earthquake," Science \& Technology Review, vol. 26, no. 10, pp. 3236, 2008 (Chinese).

[133] X.-T. Zhang, Y.-X. Zhang, and D.-H. Xu, "Investigation of the macroscopic anomalies before and after the Wenchuan M8.0 earthquake," Earthquake, vol. 29, no. 2, pp. 104-117, 2009 (Chinese).

[134] W. Cheng, X. Wu, Z. Guan, H. Zhu, and Z. Lu, "Discussion on the macroscopic anomaly phenomenae reported before the Wenchuan M8.0 earthquake," Earthquake Research in Sichuan, no. 1, pp. 1-7, 2010 (Chinese).

[135] D. Xu, "Field investigation of macro-anomalies before the Wenchuan Ms8.0 earthquake, Sichuan, China," Earthquake, vol. 30, no. 2, pp. 121-133, 2010 (Chinese).

[136] X. T. Zhang, Y. X. Zhang, and D. H. Xu, "Investigation of the macroscopic anomalies before and after the M8.0 Wenchuan earthquake," Earthquake Research in China, vol. 24, no. 1, pp. 48-69, 2010.

[137] W. Yan, C. Zhu, X. Li, and H. Zhang, "Investingation and analysis on macroscopic anomalies of earthquake before and after Wenchuan Ms8.0 earthquake in Longnan area of Gansu Province," Northwestern Seismological Journal, vol. 33, no. 1, pp. 67-70, 2011 (Chinese).

[138] Y. Li, Y. Liu, Z. Jiang et al., "Behavioral change related to Wenchuan devastating earthquake in mice," Bioelectromagnetics, vol. 30, no. 8, pp. 613-620, 2009.

[139] L. L. Chen, X. A. Hu, J. A. Zheng et al., "Increases in energy intake, insulin resistance and stress in rats before Wenchuan 
earthquake far from the epicenter," Experimental Biology and Medicine, vol. 235, no. 10, pp. 1216-1223, 2010.

[140] B. Ma, L. Wu, and S. Liu, "NDVI variation features before Wenchuan Ms8.0 earthquake," Science \& Technology Review, vol. 28, no. 13, pp. 52-57, 2010 (Chinese).

[141] Y. Li, "Possibility to detect Wenchuan M8 earthguake by the earthquake warning system," Progress in Geophysics, vol. 23, no. 7, pp. 969-971, 2008 (Chinese).

[142] F. Jiang and Q. Gao, "Application of seismo-geochemical methods for Sichuan Province in Wenchuan 8.0 magnitude earthquake of middle-term prediction succeed at according analysis," Frontier Science, vol. 3, no. 2, pp. 13-21, 2009 (Chinese).

[143] F. Y. Qian, B. R. Zhao, W. Qian et al., "Impending HRT wave precursors to the Wenchuan Ms8.0 earthquake and methods of earthquake impending prediction by using HRT wave," Science in China D, vol. 52, no. 10, pp. 1572-1584, 2009.

[144] L. S. Zhou, Z. H. Qiu, and L. Tang, "Statistical test of precursory waves before Wenchuan Ms8.0 earthquake," Journal of Geodesy and Geodynamics, vol. 29, no. 2, pp. 24-28, 2009 (Chinese).

[145] D. Rong and Y. Li, "The changing characteristics of seismic correlation length before Wenchuan M8.0 earthquake," Northwestern Seismological Journal, vol. 32, no. 1, pp. 54-58, 2010 (Chinese).

[146] L. Ming, "An explanation on short term low-temperature climate before strong earthquakes," Journal of Institute of Disaster-Prevention Science and Technology, vol. 12, no. 3, pp. 133-137, 2010 (Chinese).

[147] Z. Qiu, B. Zhang, S. Chi, L. Tang, and M. Song, "Abnormal strain changes observed at Guza before the Wenchuan earthquake," Science China Earth Sciences D, vol. 54, no. 2, pp. 233-240, 2010.

[148] S. Gao, X. Du, Y. Su et al., "The variation characteristics of precursor data in Wudu Seismic Station and the earthquake activity in the boundary area between Gansu and Sichuan Province in recent years," Northwestern Seismological Journal, vol. 31, no. 2, pp. 167-173, 2009 (Chinese).

[149] S. D. Gao, J. Tang, X. B. Du et al., "The change characteristics of electromagnetic field before to after Wenchuan Ms8.0 earthquake," Chinese Journal of Geophysics, vol. 53, no. 3, pp. 512-525, 2010 (Chinese).

[150] X. Xing, J. Mao, H. Shao, and S. Zhang, "Converted wavelet applied in analysis of well level data in Guanzhong area," Plateau Earthquake Research, vol. 21, no. 4, pp. 1-8, 2009 (Chinese).

[151] F. An, "Analysis on short-imminent anomalies of Liujiaxia deformation before Wenchuan earthquake," Plateau Earthquake Research, vol. 21, no. 2, pp. 28-31, 2009 (Chinese).

[152] S. Zhang, W. Fang, Y. Shu, J. Li, and Y. Peng, "Study on the anomaly characteristics of observation data in Zhouzhi deep borehole before Wenchuan earthquake," Journal of Institute of Disaster-Prevention Science and Technology, vol. 11, no. 1, pp. 20-27, 2009 (Chinese).

[153] X. Zhao, F. Huang, X. Wang, S. Zhang, D. Chen, and D. Shi, "Anomalous characteristics of gas Hg in Zhouzhi well, Shaanxi Province during Wenchuan Ms8.0 earthquake and its aftershocks," Inland Earthquake, vol. 24, no. 3, pp. 236240, 2010 (Chinese).

[154] J. Zhang, X. Liu, T. Tang, and J. Ma, "Research on dynamic evolution characteristics of geomagnetic field in Chinese mainland before and after Wenchuan Ms8.0 earthquake," Journal of Seismological Research, vol. 32, no. 3, pp. 231-234, 2009 (Chinese).
[155] J. Zhang, X. Liu, L. Yao, X. Ma, Y. Yuan, and X. Yin, "Study on anomalous change characters of electromagnetic disturbance before the Wenchuan Ms8.0 earthquake," Seismological and Geomagnetic Observation and Research, vol. 31, no. 5, pp. 5660, 2010 (Chinese).

[156] L. Zhang, "The typical precursor anomaly of ground fluid before Wenchuan earthquake in Yunnan region," Seismological and Geomagnetic Observation and Research, vol. 31, no. 6, pp. 40-44, 2010 (Chinese).

[157] L. Zhang, D. He, B. Shen, and Y. Su, "Probing the long-term anomaly of groundwater level of Shuifu in Yunnan area before the Wenchuan Ms8.0 earthquake," Journal of Seismological Research, vol. 33, no. 2, pp. 159-163, 2010 (Chinese).

[158] P. Qiu, Y. Wang, and G. Yang, "Analysis on underground water temperature anomaly in Qinghai before Wenchuan Ms8.0 earthquake," Journal of Institute of Disaster-Prevention Science and Technology, vol. 12, no. 1, pp. 73-78, 2010 (Chinese).

[159] Y. Zhang, X. Liu, Q. Chang, Q. Kang, and Y. Chen, “Analysis on the anomalies of Wenchuan earthquake and characteristics of postseismic effect," Plateau Earthquake Research, vol. 21, no. 3, pp. 22-27, 2009 (Chinese).

[160] P. Zhang, D. Zhang, W. Zhu, L. Fan, R. Chen, and J. Yan, "Anomalous Earth stress of the Ms8 Wenchuan earthquake in Sichuan, China-recording from piezomagnetic frequency measurement to the Earth stress," Acta Geologica Sinica, vol. 82, no. 12, pp. 1788-1799, 2008 (Chinese).

[161] Z. Song, Z. Wang, Y. Lv, S. Li, and J. Li, "Study on body strain characteristics of Xiyang Seismological Station, Shanxi, before Wenchuan, Sichuan, 8.0 earthquake and coseismic effect," Earthquake Research in Shanxi, vol. 2, pp. 19-20, 2009 (Chinese).

[162] S. Zhang, R. Liu, Y. Ning, L. Tang, and B. Li, "Analysis of characteristics of precursor wave of low frequency in Shanxi before Wenchuan Ms8.0 earthquake," Journal of Geodesy and Geodynamics, vol. 29, no. 6, pp. 35-39, 2009 (Chinese).

[163] Z. Liu, X. Yang, S. Xue, B. Li, and M. Song, "Analysis on anomalous variations in observation data of Shanxi Crustal Deformation Network before several earthquake," Earthquake Research in Shanxi, no. 2, pp. 31-33, 2010 (Chinese).

[164] J. Yang and C. Zhang, "Discussion on the correlation between metal pendulum ground tiltmeters data at Hancheng, Shannxi Seismological Station and its surrounding seismic activities," Earthquake Research in Shanxi, vol. 4, pp. 27-29, 2010 (Chinese).

[165] M. Li, J. Lu, Y. Chang, and X. Liu, "ULF electromagnetic anomaly observed at Gaobeidian and Ningjin seismic stations before Wenchuan 8.0 earthquake," Recent Developments in World Seismology, vol. 7, pp. 76-82, 2009 (Chinese).

[166] H. Yin, J. Li, X. Dong, and P. Xu, "On characteristics of crustal movement of Shandong and surrounding areas before and after Wenchuan Ms8.0 earthquake," Journal of Geodesy and Geodynamics, vol. 29, no. 3, pp. 23-27, 2009 (Chinese).

[167] S. Lu, Q. Wang, X. Lin et al., "Analysis of anomalies about pendulum tiltmeter at Taian seismostation before Wenchuan earthquake," Journal of Geodesy and Geodynamics, vol. 31, supplement, pp. 19-23, 2011 (Chinese).

[168] S. Su, J. Li, Q. Zhang, S. Yang, and Z. Song, "The response of crustal deformation data in Yixian Seismic Station to Wenchuan Ms8.0 earthquake," North China Earthquake Sciences, vol. 27, no. 2, pp. 54-58, 2009 (Chinese).

[169] J. Zhang, G. Zhao, J. Wang, T. Tang, and L. Qi, "Preliminary study on the relationship between the Ms8.0 Wenchuan earthquake of 2008 and the anomalies of earth resistivity 
observed at Qingdao seismic station," Seismology and Geology, vol. 32, no. 3, pp. 409-416, 2010 (Chinese).

[170] H. Zhang, J. Guo, Z. Xue, C. Yu, F. Li, and J. Zhou, "Analysis on geothermal and water level response to Wenchuan earthquake in Changli Well," North China Earthquake Sciences, vol. 27, no. 4, pp. 46-49, 2009 (Chinese).

[171] D. Liu, "Discussion on relation between anomalies of water temperature and Radon in Ningbo station and Wenchuan Ms8.0 earthquake," Journal of Geodesy and Geodynamics, vol. 28, no. 6, pp. 53-55, 2008 (Chinese).

[172] J. Zhang, J. Ding, X. Shen et al., "Abnormal count rate of Yangbajing neutron-muon telescope before Wenchuan earthquake," Chinese Journal of Radio Science, vol. 25, no. 2, pp. 227-233, 2010 (Chinese).

[173] J. Wang, Y. Chen, Z. Ye, and S. Liu, "Property analysis of cosmic rays before and during the great Wenchuan earthquake," Progress in Geophysics, vol. 25, no. 1, pp. 137-142, 2010 (Chinese).

[174] B. Deng, M. Yang, J. Huang, and W. Zhao, "Study on VTEC anomaly of ionosphere in south China before and after Wenchuan earthquake," South China Journal of Seismology, vol. 29, no. 4, pp. 8-15, 2009 (Chinese).

[175] M. Yang, B. Deng, W. Zhao, and J. Huang, "Study on abnormal characteristics of ionosphere TEC above SouthChina responding to two strong earthquakes," Journal of Geodesy and Geodynamics, vol. 29, no. 6, pp. 13-17, 2009 (Chinese).

[176] W. Bo and G. Yang, "Crustal deformation measured by mobile observation before Wenchuan Ms8.0 earthquake," Journal of Geodesy and Geodynamics, vol. 28, no. 6, pp. 11-15, 2008 (Chinese).

[177] G. Zhao, W. Ma, J. Wang, and A. He, "Geothermal earthquake precursor network and its response to Ms8.0 Wenchuan earthquake," Journal of Seismological Research, vol. 32, no. 3, pp. 248-252, 2009 (Chinese).

[178] I. P. Dobrovolsky, S. I. Zubkov, and V. I. Miachkin, "Estimation of the size of earthquake preparation zones," Pure and Applied Geophysics, vol. 117, no. 5, pp. 1025-1044, 1979.

[179] X. G. Hu and X. G. Hao, "The short-term anomalies detected by broadband seismographs before the May 12 Wenchuan earthquake, Sichuan, China," Chinese Journal of Geophysics, vol. 51, no. 6, pp. 1726-1734, 2008 (Chinese).

[180] X. G. Hu and X. G. Hao, "An analysis of the influences of typhoon on anomalous tremors before the great Wenchuan and Kunlunshan earthquakes," Chinese Journal of Geophysics, vol. 52, no. 5, pp. 1363-1375, 2009 (Chinese).

[181] R. S. Fu, K. S. Wan, J. J. Chong, and T. X. Xue, "Earthquake auspice or other factor? Discuss with authors of the paper "The short-term anomalies detected by broadband seismographs before the May 12 Wenchuan earthquake, Sichuan, China"'" Chinese Journal of Geophysics, vol. 52, no. 2, pp. 584589, 2009 (Chinese).

[182] X.-G. Hu, X.-G. Hao, and X.-X. Xue, "The analysis of the non-typhoon-induced microseisms before the 2008 Wenchuan earthquake," Chinese Journal of Geophysics, vol. 53, no. 12, pp. 2875-2886, 2010 (Chinese).

[183] Z. H. Qiu, L. S. Zhou, and S. L. Chi, "Study on precursory strain changes of Wenchuan earthquake with ORA method," Journal of Geodesy and Geodynamics, vol. 29, no. 4, pp. 1-4, 2009 (Chinese).

[184] Z. H. Qiu, L. Tang, L. S. Zhou, and B. X. Kan, "Observed strain changes from 4-component borehole strainmeter network before 2008 Wenchuan earthquake," Journal of Geodesy and Geodynamics, vol. 29, no. 1, pp. 1-5, 2009 (Chinese).
[185] Q. Su, H. Zhu, and Y. Yang, "Short-line leveling anomaly at Gengda and Wenchuan Ms8.0 earthquake," Journal of Geodesy and Geodynamics, vol. 29, supplement, pp. 103-105, 2009 (Chinese).

[186] J. Wei, H. Hao, K. Kang et al., "Gravity disturbance of high frequcncy at Chengdu seismostation before Wenchuan Ms8.0 earthquake," Journal of Geodesy and Geodynamics, vol. 29, supplement, pp. 15-19, 2009 (Chinese).

[187] W. Liu, H. Chen, F. Zhao, X. Liu, B. Yuan, and J. Zhang, "Characteristics of spatio-temporal relation of strong earthquakes in China before and after the Sichuan Wenchuan Ms8.0 earthquake," Earthquake, vol. 30, no. 3, pp. 140-146, 2010 (Chinese).

[188] H. Zhu, J. P. Deng, and G. Yang, "Discussion on the causes of 2 anomalies before the Wenchuan M8.0 earthquake," Earthquake Research in Sichuan, no. 1, pp. 13-17, 2010 (Chinese).

[189] H. Zhu, Q. Su, T. Yang, X. Z. Wen, and S. X. Wang, "Identifying anomalous change of short-line leveling on Gengda site pre- and after Ms8.0 Wenchuan earthquake," Acta Seismologica Sinica, vol. 32, no. 6, pp. 649-658, 2010 (Chinese).

[190] W. Cheng, Q. Su, and Y. Sun, "Study on the datum anomalies of crust deformation in Sichuan region before the 2008 M8.0 Wenchuan earthquake," Earthquake Research in Sichuan, no. 1, pp. 1-10, 2011 (Chinese).

[191] W. Cheng, Y. Ren, and X. Wu, "Analyzing the anomalies of geo-electrical and geo-magnetic observation data in Sichuan Province before the 2008 Wenchuan M8.0 earthquake," Earthquake Research in Sichuan, no. 2, pp. 2-9, 2010 (Chinese).

[192] P. Cheng, J. Mi, H. Wang, Y. Cai, and Y. Huang, "Timevariations of some domestic IGS sites during the Wenchuan earthquake," GNSS World of China, vol. 33, no. 5, pp. 11-15, 2008 (Chinese).

[193] J. Liu, "On geothermal earthquake observation network and Wenchuan 8.0 earthquake," Journal of Institute of DisasterPrevention Science and Technology, vol. 12, no. 3, pp. 48-54, 2010 (Chinese).

[194] P. Qiu, Y. Wang, G. Yang, X. Bai, and S. Zhao, "Research on the anomalous changes of water surface temperature before and after Wenchuan Ms8.0 earthquake," Northwestern Seismological Journal, vol. 32, no. 4, pp. 367-375, 2010 (Chinese).

[195] J. Dong, R. Yan, J. Zhang, X. Zhang, and J. Liu, "Analysis of earthquake-related information in ionosphere based on DEMETER satellite data-applicated to Wenchuan and Donghai earthquakes," Earthquake, vol. 29, supplement, pp. 67-75, 2009 (Chinese).

[196] G. Gu and W. Wang, "Vertical crustal movement before and after the great Wenchuan earthquake obtained from GPS observations in the regional network," Earthquake, vol. 31, no. 3, pp. 1-8, 2011 (Chinese).

[197] W. Bo and L. Zhang, "The Ms8.0 Wenchuan earthquake: precursor analysis of fault deformation," Journal of Seismological Research, vol. 31, supplement, pp. 419-423, 2008 (Chinese).

[198] S. Zhang, X. Zhang, S. Wang, F. Xue, and L. Liu, "Analysis of crustal vertical deformation before and after Wenchuan Ms8.0 earthquake," Journal of Geodesy and Geodynamics, vol. 28, no. 6, pp. 43-46, 2008 (Chinese).

[199] Z.-S. Jiang, Y.-Q. Wu, Y. Fang, P. Li, and W.-X. Wang, "Dynamic characteristics of the strain fields and crustal movements before the Wenchuan Ms8.0 earthquake," Earthquake, vol. 29, no. 1, pp. 68-76, 2009 (Chinese).

[200] Z.-S. Jiang, Y. Fang, Y.-Q. Wu, M. Wang, F. Du, and J.-J. Ping, "The dynamic process of regional crustal movement and 
deformation before Wenchuan Ms8.0 earthquake," Chinese Journal of Geophysics, vol. 52, no. 2, pp. 505-518, 2009 (Chinese).

[201] X. Shan, X. Song, Y. Han, C. Qu, G. Zhang, and G. Zhang, "The characteristics of surface vertical deformation before the Wenchuan Ms8.0 earthquake from InSAR," Chinese Journal of Geophysics, vol. 52, no. 11, pp. 2739-2745, 2009 (Chinese).

[202] R. Xie, Q. Li, J. Qin, R. Zhang, S. Xu, and J. Feng, "Study on gravity change around Wenchuan Ms8.0 earthquake recorded in Ji-Lu-Yu junction area," Journal of Geodesy and Geodynamics, vol. 29, no. 1, pp. 27-30, 2009 (Chinese).

[203] G. A. Yang and Y. Mi, "Thermal anomalies and earthquakes: evidence from Wenchuan, China," Earthquake Research in China, vol. 23, no. 1, pp. 48-55, 2009.

[204] Q. Cui, Y. Shu, Z. Wang, J. Fan, and W. Liu, "Suspected correlation between anomalies of body strain observation data at Xi'an Seismological Station and Wenchuan M8.0 earthquake," Earthquake Research in Shanxi, no. 4, pp. 30-33, 2010 (Chinese).

[205] J. Shi, W. Wang, and J. Wen, "The meteorological anomalies before and after the Wenchuan earthquake," Astronomical Research \& Technology, vol. 7, no. 1, pp. 78-84, 2010 (Chinese).

[206] L. Wu, L. Zhang, G. Li, and H. Guo, "The relative calibration and its application of 4-component borehole strain observation in HaiYuan Station," Journal of Seismological Research, vol. 33, no. 4, pp. 318-322, 2010 (Chinese).

[207] W.-B. Liu, "Reverse tracing of the seismicity before strong earthquakes in Mainland China," Earthquake, vol. 30, no. 2, pp. 46-53, 2010 (Chinese).

[208] Z. Chen, P. Lu, Z. Li, B. Zhao, and S. Lin, "Analysis of tidal data before Wenchuan Ms8.0 earthquake," Journal of Geodesy and Geodynamics, vol. 29, no. 4, pp. 48-50, 2009 (Chinese).

[209] X.-F. Fan, J.-Y. Wang, and M.-Y. Lu, "Preliminary study on some typical medium-term subsurface fluid anomalies before the Wenchuan 8.0 earthquake," Earthquake, vol. 29, no. 1, pp. 132-140, 2009 (Chinese).

[210] Y. Ding, H. Chen, and J. Zhang, "The preliminary research on anomalous variation character of electromagnetic radiation before the Wenchuan Ms8.0 earthquake," Seismological and Geomagnetic Observation and Research, vol. 30, no. 3, pp. 1115, 2009 (Chinese).

[211] S. Zhou, Y. Wu, S. Shi, and Z. Chen, "Anomalous change of fault deformation before Wenchuan Ms8.0 earthquake and its comparison with response of other large earthquakes," Acta Seismologica Sinica, vol. 31, no. 2, pp. 140-151, 2009 (Chinese).

[212] S.-R. Mei, Y. Xue, and Z.-P. Song, "Anomalous seismic characteristics before Wenchuan M8.0 and Kunlunshan M8.1 earthquakes and their implications," Earthquake, vol. 29, no. 1, pp. 1-14, 2009 (Chinese).

[213] L. Chen, H. Fu, and X. Zhao, "Comparative study of $M \geq 5$ seismic activities before some large earthquakes," Earthquake, vol. 30, no. 4, pp. 22-31, 2010 (Chinese).

[214] W. Cheng and Y. Zhang, "Discussion on the seismicity and seismic tendency of Sichuan Province before the 2008 Wenchuan M8.0 earthquake," Earthquake Research in Sichuan, no. 3, pp. 1-7, 2009 (Chinese).

[215] L. Chen and H. Fu, "The contrast study of Wenchuan M8.0 earthquake precursor anomalies," Inland Earthquake, vol. 24, no. 4, pp. 289-297, 2010 (Chinese).

[216] T. H. Jordan, Y. T. Chen, P. Gasparini et al., "Operational earthquake forecasting: state of knowledge and guidelines for utilization," Annals of Geophysics, vol. 54, no. 4, pp. 315-391, 2011.
[217] A.-F. Niu, L.-K. Zhang, W. Yan, X.-D. Jia, and X.-F. Li, "On the characteristics of ground deformation anomalies in the middle and northern part of the south-north seismic belt prior to the Wenchuan earthquake," Earthquake, vol. 29, no. 1, pp. 100-107, 2009 (Chinese).

[218] L. Zhang, M. Yu, and D. Sun, "Analysis on fault deformation anomaly of Longmenshan fault zone before Ms8.0 Wenchuan strong earthquake," North China Earthquake Sciences, vol. 27, no. 1, pp. 34-38, 2009 (Chinese).

[219] M.-Y. Lu, Z.-F. Fang, and L.-K. Zhao, "Discussion on the long-time trend change characteristics of subsurface fluid before the Wenchuan Ms8.0 earthquake," Earthquake, vol. 30, no. 1, pp. 61-72, 2010 (Chinese).

[220] H. Zhang, Z. Ouyang, Z. Fu, B. Gou, and W. Jiang, "Abnormal phenomena recorded by several earthquake precursor observation instruments before the Ms8.0 Wenchuan, Sichuan earthquake," Progress in Geophysics, vol. 26, no. 1, pp. 99-109, 2011 (Chinese).

[221] Y. Zhu, W. Liang, and Y. Xu, "Medium-term prediction of Ms8.0 earthquake in Wenchuan, Sichuan by mobile gravity," Recent Developments in World Seismology, no. 7, pp. 36-39, 2008 (Chinese).

[222] M. Wyss, Ed., Evaluation of Proposed Earthquake Precursors, American Geophysical Union, Washington, DC, USA, 1991.

[223] M. Wyss and R. Dmowska, Eds., "Earthquake Prediction, State-of-the-Art," Pure and Applied Geophysics, vol. 149, no. 1, pp. 1-264, 1997.

[224] R. D. Cicerone, J. E. Ebel, and J. Britton, "A systematic compilation of earthquake precursors," Tectonophysics, vol. 476, no. 3-4, pp. 371-396, 2009.

[225] T. Rikitake, Earthquake Prediction, Elsevier, New York, NY, USA, 1976.

[226] T. Rikitake, "Classification of earthquake precursors," Tectonophysics, vol. 54, no. 3-4, pp. 293-309, 1979.

[227] T. Rikitake, "Earthquake prediction: an empirical approach," Tectonophysics, vol. 148, no. 3-4, pp. 195-210, 1988.

[228] K. Mogi, Earthquake Prediction, Academic Press, Orlando, Fla, USA, 1985. 

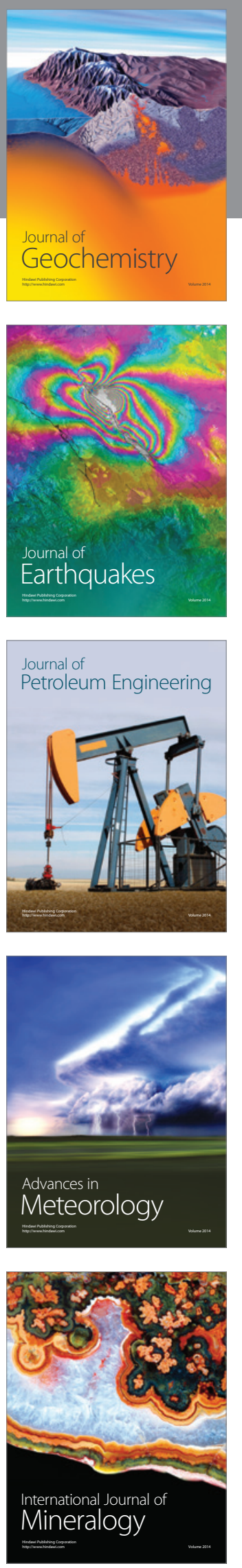
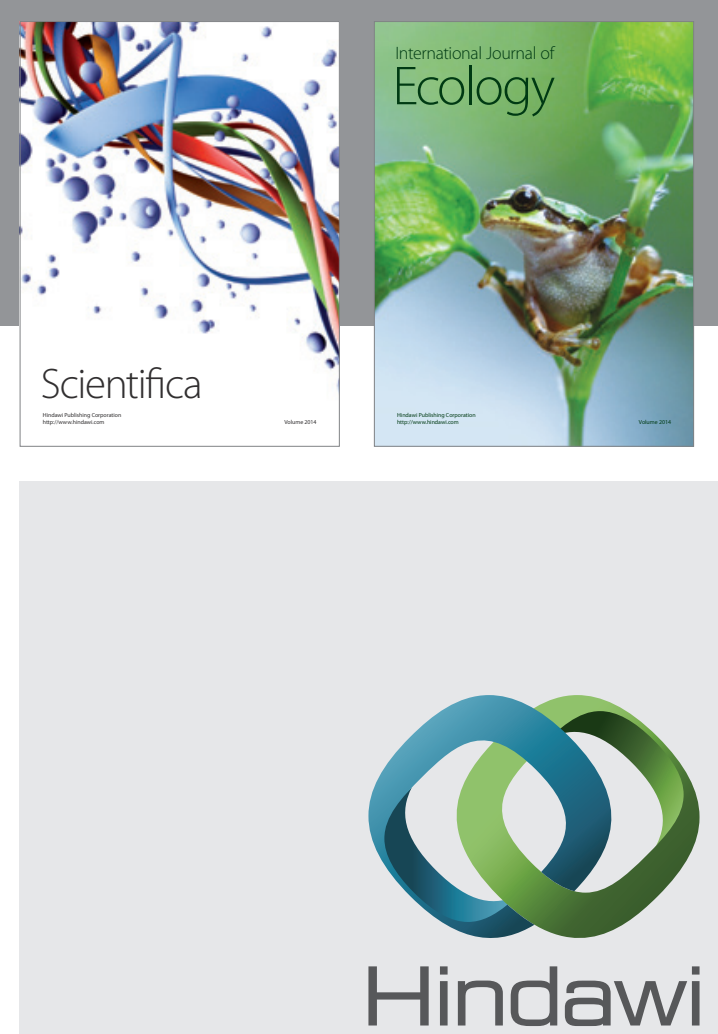

Submit your manuscripts at http://www.hindawi.com
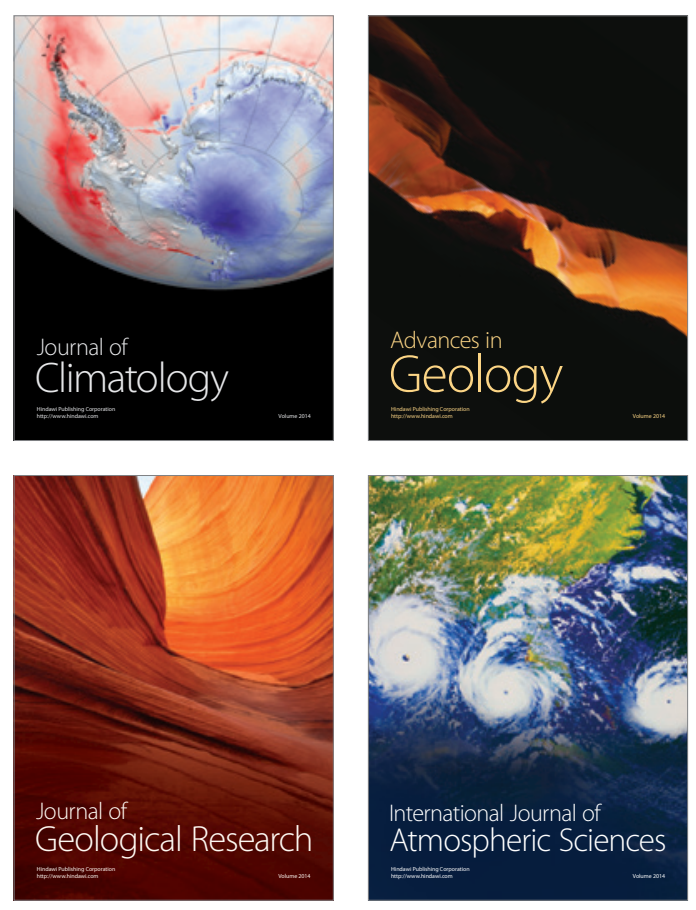
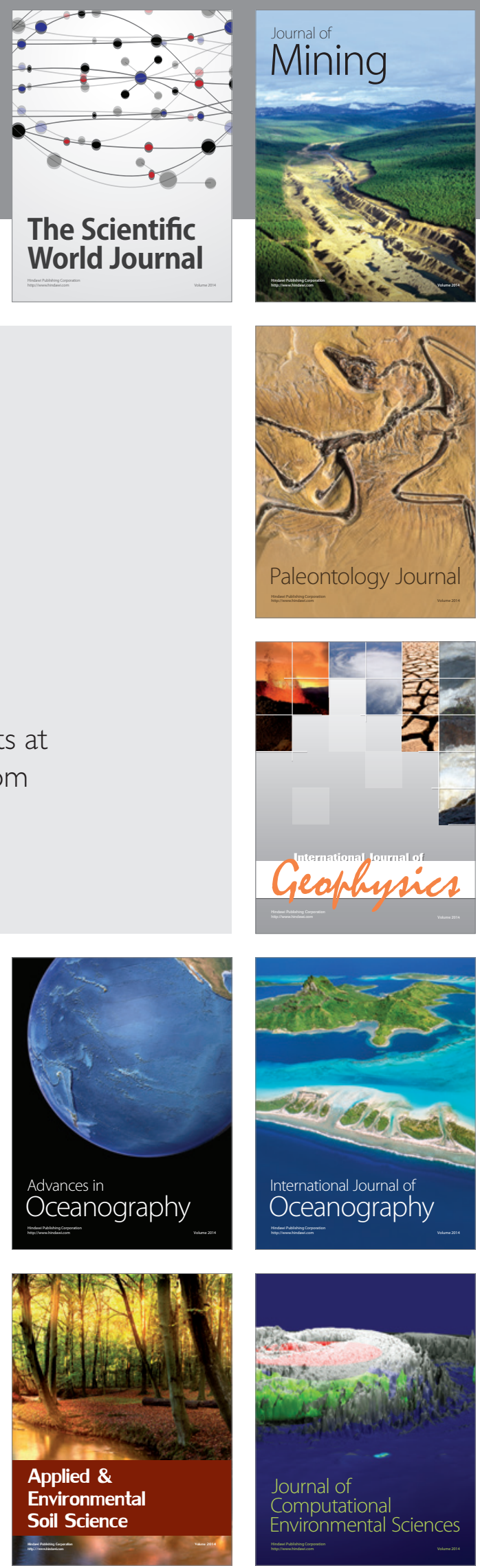